\title{
Sars CoV2, una experiencia de la bioquímica en contexto para la enseñanza de conceptos asociados a las proteínas.
}

\section{Sars CoV 2, an experience of biochemistry in context for teaching concepts associated with proteins.}

\author{
Rodrigo Rodríguez Cepeda \\ Universidad Pedagógica Nacional, Bogotá, Colombia. \\ rrodriguez@pedagogica.edu.co \\ María José Cortés Parra \\ Universidad Pedagógica Nacional, Bogotá, Colombia. \\ dqu_mjcortesp747@pedagogica.edu.co
}

\begin{abstract}
Resumen
El presente artículo muestra los resultados de una intervención didáctica en el marco de la enseñanza de la bioquímica en contexto, con el fin de enseñar algunos conceptos asociados a las proteínas, para un grupo de estudiantes del programa de Licenciatura en Química de la Universidad Pedagógica Nacional. Por esta razón, se abordó el tema del Covid 19, especialmente las proteínas del coronavirus Sars CoV 2 con el fin de enseñar conceptos como: aminoácidos, enlace peptídico, proteínas, estructura primaria y secundaria de las proteínas. De ahí que, los estudiantes trabajaron alrededor de videos explicativos del coronavirus, lecturas de artículos académicos sobre la estructura del virus, conferencias, así como el uso de la bioinformática para diseñar estructuras y predecir las estructuras primaria y secundaria de las proteínas. El desempeño académico de los estudiantes fue determinado mediante un cuestionario inicial, otro final y un resumen escrito en forma de artículo, como resultado, se pudo observar que el uso de estas herramientas didácticas, aplicadas en el contexto de la pandemia, mejora el desempeño académico de los estudiantes, toda vez que los estudiantes fueron capaces de elaborar las diferentes estructuras de una fracción de proteína, incluyendo sus respectivas características.
\end{abstract}

Palabras Clave: Bioquímica, herramientas bioinformáticas, Ambiente virtual, herramientas docentes, aprendizaje en contexto.

\begin{abstract}
This article shows the results of a didactic intervention in the field of teaching biochemistry in context, to teach some concepts associated with proteins. The participants were fourteen students enrolled in the Bachelor of Chemistry program of the National Pedagogical University, with whom the subject of COVID 19 was worked, and emphasis was placed on the proteins of the coronavirus Sars CoV 2, to teach concepts such as amino acids, peptide bond, proteins, primary, and secondary protein structures. Thus, activities such as explanatory videos of the coronavirus, readings of academic articles on the structure of the virus, lectures, as well as the use of bioinformatics tools to design and predict protein structures were carried out. The academic performance of the students was evaluated through mental maps, initial and final questionnaires, as well as an essay. As a result, it could suggest that the use of these didactic tools, applied in the context of the pandemic, improves academic performance, since the students were able to elaborate the different structures of a protein fraction, including their respective characteristics.
\end{abstract}

Keywords: Biochemistry, bioinformatics tools, Virtual environment, teaching tools, learning in context. 


\section{Introducción}

Desde el desarrollo de equipos instrumentales de análisis como el microscopio, los espectrofotómetros y cromatógrafos, entre otros, las ciencias naturales han visto un desarrollo amplio en sus investigaciones. No obstante, en la actualidad, la química, bioquímica y la biología prácticamente no se podrían concebir sin la bioinformática (Badotti, Barbosa, Martins, Do Valle, \& Mainá, 2014). Por esta razón, es importante que en los cursos de bioquímica se adopten estas herramientas con el fin de facilitar el aprendizaje de conceptos bioquímicos. Diversas investigaciones han reportado el uso de herramientas bioinformáticas en procesos de enseñanza aprendizaje de la bioquímica con resultados académicos favorables (Lohning, Hall, \& Dukie, 2019; Sun, Tang, Sa, \& Gao, 2019).

Por otra parte, es claro que la bioquímica abarca una información muy amplia y compleja, por ejemplo: ciclos metabólicos, mecanismos de reacción, estructuras orgánicas y estructuras tridimensionales complicadas, entre otros aspectos, que la hacen difícil para los estudiantes, y generan consecuencias poco favorables en la construcción de conceptos como: problemas de aprendizaje, errores conceptuales, aprendizaje memorístico o desmotivación (Nagaiah, Gowda, \& Jeyachristy, 2014 ; Mutlu, 2018). Razón por la cual, es importante que en los cursos de bioquímica se vinculen las herramientas bioinformáticas y la enseñanza de la bioquímica en contexto, con el fin de motivar al estudiante y minimizar las dificultades de aprendizaje, toda vez que, la enseñanza en contexto ha demostrado buenos resultados en los procesos de enseñanza y aprendizaje de la química y la bioquímica (Rodriguez, Casas, \& Martínez, 2020).

En este contexto, el presente trabajo planteó como objetivo aplicar algunas actividades didácticas encaminadas a la enseñanza de los conceptos: aminoácidos, enlace peptídico, proteínas, estructura primaria y estructura secundaria de las proteínas, en el contexto del coronavirus Sars CoV 2, responsable de la enfermedad Covid 19, entre las cuales se destaca, la realización de un video introductorio, indagación de artículos académicos alrededor del coronavirus, así como el uso de herramientas bioinformáticas. Los resultados de aprendizaje fueron evaluados mediante un cuestionario pre y pos aplicación, así como mediante cuestionarios y documentos escritos a manera de artículo por parte de los estudiantes, los datos recolectados se analizaron mediante el uso del software Atlas.ti.

\section{Antecedentes}

Los cursos de bioquímica son considerados complejos, por lo que el aprendizaje memorístico predomina sobre el aprendizaje significativo que perdura en el tiempo, una de las evidencias son los laboratorios de bioquímica, generalmente orientados mediante protocolos paso a paso conduciendo a que los estudiantes no tengan la oportunidad de entender lo que hacen, o que finalidad se pretenda (Boyd-Kimball \& Miller, 2018). De la misma manera, conceptos relacionados con procesos que ocurren a nivel molecular como por ejemplo, la formación de enlaces peptídicos, estructuras de las proteínas o las vías metabólicas son poco comprendidas por los estudiantes, se crean errores conceptuales y se abordan con temor, por lo que, la enseñanza de la bioquímica emerge como un desafío para los profesores, quienes deben generar vías alternativas para su enseñanza. (Dorfman, Terrill, Patterson, Yarden, \& Blonder, 2019; Fardilha, Schrader, da Cruz e Silva, \& da Cruz e Silva, 2010; Lang \& Bodner, 2020).

Sars CoV2, una experiencia de la bioquímica en contexto para la enseñanza de conceptos asociados a las proteínas. Rodrigo Rodríguez Cepeda y María José Cortés Parra.

Página 2 de 20 
En este sentido, la enseñanza de las ciencias en contexto ha demostrado que favorece el aprendizaje de conceptos, especialmente porque enfrenta a los estudiantes con situaciones relevantes de la vida real, algunos modelos utilizados en estos procesos son la resolución de problemas, el aprendizaje por investigación o el modelo de Ciencia Tecnología y Sociedad (CTSA) (Macaulay, Van Damme, \& Walker, 2009 ; Michael, 2006). En estos modelos, en contraste con el modelo tradicional memorístico explicativo, el cual se especializa en exposiciones de hechos y conceptos, el profesor asume el rol de orientador quien apoya el aprendizaje del estudiante, quien desarrolla procedimientos propios para dar respuesta a preguntas de investigación, o para explicar problemas que afectan a la sociedad (Wheeler, Maeng, \& Whitworth, 2015).

Algunas investigaciones han recomendado utilizar una metodología multifacética, incorporando numerosos enfoques que incluyen el aprendizaje cooperativo, enfoques con casos clínicos, mapas conceptuales, modeladores virtuales, multimedia, webinars, entre otras, las cuales han mostrado resultados positivos en aspectos como: el rendimiento académico de los estudiantes, la motivación por el aprendizaje de conceptos bioquímicos y la reducción en los errores conceptuales (Cookmeyer, et. Al., 2017; Lohning, Hall, \& Dukie, 2019). Además, el aprendizaje en contexto tiene la posibilidad de ser utilizado con enfoques combinados mediante el uso de herramientas propias de la bioinformática, asistida por el internet y en general con el uso de las Tecnologías de la Información y la Comunicación (TIC) (Macaulay, Van Damme, \& Walker, 2009 ; Vaughan, 2007).

Por otra parte, es claro que los procesos de enseñanza aprendizaje de conceptos asociados a las proteínas, como por ejemplo sus estructuras tridimensionales, la funcionalidad, y las vías metabólicas, revisten gran dificultad en los estudiantes debido a su complejidad, por lo que estudiantes y profesores abordan estas temáticas de forma muy superficial y muchas veces con metodologías expositivas, las cuales producen un mayor desinterés por su correcto aprendizaje, es así como, en la revisión de antecedentes, se encuentran trabajos en los que se evidencia un entendimiento fraccionado sobre la estructuras tridimensional de la proteína, especialmente cuando los estudiantes tratan de elaborar conexiones relacionadas entre las estructuras primaria, secundaria, terciaria y cuaternaria (Linenberger \& Bretz, 2014; Rodríguez, Hux, Philips, \& Towns, 2019).

Además de esto, Berry y Baker (2010) mencionan que es difícil explicar con claridad la complejidad tridimensional de las estructuras propias de las proteínas, al utilizar proyecciones en dos dimensiones, por lo que, la disponibilidad de software de visualización molecular capaz de generar gráficas en 3D, son una solución económica para complementar y apoyar la enseñanza de la bioquímica (Berry \& Baker, 2010). Uno de los aspectos más relevantes de este problema es que los estudiantes logren entender que todas las interacciones moleculares son mediadas por superficies de interacción, por ejemplo la interacción de las enzimas con los sustratos.

Sin embargo, existen trabajos donde resaltan que la sola representación tridimensional no le permite al estudiante comprender las interacciones moleculares, por lo que es necesario complementar con múltiples representaciones para generar una real estructuración mental (Schönborn \& Anderson , 2006), además de implementar modelos de enseñanza alejados del tradicional conductista memorístico, teniendo en cuenta las particularidades de los estudiantes, sus intereses y sus inquietudes. También es importante que los profesores incluyan tutorías como parte esencial en la formación de los estudiantes, especialmente para aquellos que tienen dificultades de aprendizaje (Rodríguez R. , 2018).

Sars CoV2, una experiencia de la bioquímica en contexto para la enseñanza de conceptos asociados a las proteínas. Rodrigo Rodríguez Cepeda y María José Cortés Parra.

Página 3 de 20 
Por otra parte, los avances en las tecnologías de la información y la comunicación (TIC), han permitido contar con abundante información en tiempo real, lo cual ha llevado a un nuevo paradigma educativo que se relaciona con las nuevas herramientas educativas de internet, conocidas como Web 2.0, herramientas que facilitan los procesos de enseñanza aprendizaje, ya que son atractivas para los estudiantes (Romero, Espinosa, \& Ramírez, 2019). En este sentido, en la tabla 1 se presenta un resumen de algunas herramientas bioinformáticas que pueden ser encontradas en internet.

Tabla 1: Herramientas bioinformáticas para la enseñanza de las proteínas

\begin{tabular}{|c|c|c|}
\hline $\begin{array}{l}\text { Herramienta } \\
\text { Bioinformática }\end{array}$ & Dirección & Propósito \\
\hline RCSB PDB & http://www.rcsb.org/ & $\begin{array}{l}\text { Contiene una base de } \\
\text { datos con estructuras en } \\
\text { 3D de proteínas y ácidos } \\
\text { nucleicos (Berman, y } \\
\text { otros, 2000) }\end{array}$ \\
\hline Pubchem & https://pubchem.ncbi.nlm.nih.gov/ & $\begin{array}{l}\text { Es una base de datos } \\
\text { abierta con moléculas } \\
\text { como nucleótidos, } \\
\text { péptidos, carbohidratos y } \\
\text { lípidos (Kim, y otros, } \\
2019 \text { ) }\end{array}$ \\
\hline ChemAxon & https://chemaxon.com/ & $\begin{array}{l}\text { Contiene diferentes } \\
\text { plataformas de gestión de } \\
\text { datos para diseñar } \\
\text { moléculas, cálculo de } \\
\text { propiedades, } \\
\text { (Chemaxon, 1998) }\end{array}$ \\
\hline $\begin{array}{l}\text { Python } \\
\text { Prescription }\end{array}$ & https://pyrx.sourceforge.io/home & $\begin{array}{l}\begin{array}{l}\text { Software para realizar } \\
\text { docking }\end{array} \\
\text { molecular } \\
\text { (Dallakyan \& } \\
\text { 2015) }\end{array}$ \\
\hline Psipred & http://bioinf.cs.ucl.ac.uk/psipred/ & $\begin{array}{l}\text { Plataforma creada por el } \\
\text { grupo de bioinformática } \\
\text { de University College } \\
\text { London, permite predecir } \\
\text { las estructuras de las } \\
\text { proteínas (Buchan \& } \\
\text { Jones, 2019) }\end{array}$ \\
\hline $\begin{array}{l}\text { Uppsala } \\
\text { Ramachandran } \\
\text { server }\end{array}$ & http://eds.bmc.uu.se/ramachan.html & $\begin{array}{l}\text { Permite generar la } \\
\text { gráfica de Ramachandran } \\
\text { para las estructuras que } \\
\text { están almacenadas en el } \\
\text { PDB (Kleywget \& Jones, } \\
\text { 1996) }\end{array}$ \\
\hline
\end{tabular}

Sars CoV2, una experiencia de la bioquímica en contexto para la enseñanza de conceptos asociados a las proteínas. Rodrigo Rodríguez Cepeda y María José Cortés Parra. 
Además de lo anterior, existen investigaciones en las cuales se ha encontrado que el uso de herramientas bioinformáticas, fomentan el trabajo colaborativo, la investigación activa y el desarrollo de habilidades para utilizar e interpretar datos bioinformáticos (Smith, Harris, López, Valverde , \& Borchert, 2015), aspectos importantes, teniendo en cuenta que en la actualidad, las investigaciones en bioquímica y biología molecular, demandan la exploración automática de datos. De ahí que, muchos programas de pregrado y posgrado han incorporado cursos completos de bioinformática, tendientes a la formación de una nueva generación de profesionales e investigadores de alto nivel en bioinformática y campos relacionados (Koch \& Fuellen, 2008).

Además de lo anterior, existen diversos trabajos enfocados al uso de la bioinformática como herramienta de enseñanza, por ejemplo, para promover la visualización de procesos y estructuras teóricamente complejas como la replicación, transcripción y traducción de información genética, o las interacciones entre monómeros como aminoácidos o nucleótidos en la formación de macromoléculas, o en el desarrollo de laboratorios de introducción a la bioinformática centrados en el análisis de proteínas (Rowe, 2017; Stasinakis \& Despoina, 2017; Zardecki, Dutta, Goodsell, Voigt, \& Burley, 2016).

Las reflexiones anteriores permiten suponer que es posible diseñar y aplicar un curso de bioquímica en contexto, donde se utilicen herramientas bioinformáticas y otras presentes en la Web 2.0 como foros, blogs, videos o plataformas de gestión de aprendizaje (Learning Content Management), integradas al uso de textos y artículos científicos, con el fin de mejorar el rendimiento académico de los estudiantes de ciencias.

\section{Metodología}

La metodología de la presente investigación se enmarcó en los lineamientos cuasiexperimentales sin grupo control, la cual incluye una serie de actividades que involucran el diseño de instrumentos para evaluar el rendimiento académico, observación y análisis de videos, lectura de artículos académicos, uso de recursos bioinformáticos, elaboración de un informe tipo artículo y cuestionario final. Las actividades se diseñaron en el contexto del virus Sars Cov 2 y se organizaron en tres etapas:

En primer lugar se diseñaron y seleccionaron los instrumentos de evaluación entre los que se destaca el uso de mapas conceptuales, mapas mentales y redes de conceptos, los cuales permitieron evidenciar la estructura cognitiva y la inclusión de nuevos conceptos en la medida que se avanza en el aprendizaje.

Igualmente, se utilizó un cuestionario de preguntas abiertas, con el fin de identificar conceptos de interés e inquietudes surgidas durante la actividad inicial de observación de un video y una conferencia introductoria. Este instrumento se evaluó con el software Atlas.ti.

Por otra parte, las actividades que incluían el uso de las herramientas bioinformáticas se evaluaron mediante la elaboración de un ensayo y un artículo reflexivo, los cuales, mediante el software Atlas.ti, permitieron elaborar redes conceptuales que facilitaron evaluar la inclusión o no de nuevos conceptos en la estructura cognitiva.

Por último, la eficacia del uso de las herramientas bioinformáticas se evaluaron mediante la elaboración de un dibujo de la estructura secundaria de una fracción de proteína, la

Sars CoV2, una experiencia de la bioquímica en contexto para la enseñanza de conceptos asociados a las proteínas. Rodrigo Rodríguez Cepeda y María José Cortés Parra. 
distribución de cargas y el cálculo del punto isoeléctrico, lo cual permitió observar si los enlaces peptídicos, la formación de puentes, la distribución de carga estaban correctos.

\section{Estudiantes Participantes}

Para el desarrollo del presente estudio se utilizó una muestra de treinta estudiantes de tercer año de pregrado, registrados en un curso introductorio a la bioquímica, ofertado por el programa de Licenciatura en Química de la Universidad Pedagógica Nacional de Bogotá - Colombia. Los conceptos abordados en este estudio son acordes al programa definido por la universidad y los estudiantes fueron debidamente informados del estudio, por lo que estaban plenamente conscientes y de quienes se recibió su respectivo consentimiento.

\section{Actividad educativa}

Para el desarrollo del presente estudio se realizó la secuencia de actividades que se presenta en la tabla 2.

Tabla 2: Actividades educativas desarrolladas

\begin{tabular}{|c|c|c|}
\hline Actividad & $\begin{array}{l}\text { Descripción } \\
\end{array}$ & Herramienta utilizada \\
\hline $\begin{array}{l}\text { Video introducción } \\
\text { coronavirus }\end{array}$ & $\begin{array}{l}\text { Naturaleza del Coronavirus. } \\
\text { Conceptos básicos de } \\
\text { virología. } \\
\text { Características estructurales } \\
\text { del Sars Cov } 2 \text {. }\end{array}$ & Microsoft teams \\
\hline $\begin{array}{l}\text { Elaboración mapa } \\
\text { conceptual }\end{array}$ & $\begin{array}{l}\text { Mapa conceptual o mental } \\
\text { resumen del video }\end{array}$ & \multirow{3}{*}{$\begin{array}{c}\text { Presentaciones en } \\
\text { power point vía Teams. }\end{array}$} \\
\hline $\begin{array}{l}\text { Conferencia: } \\
\text { Aminoácidos, péptidos y } \\
\text { proteínas, distribución de } \\
\text { cargas, punto isoeléctrico }\end{array}$ & $\begin{array}{l}\text { Explicación de conceptos } \\
\text { básicos de proteínas (lectura } \\
\text { de artícuos). }\end{array}$ & \\
\hline $\begin{array}{c}\text { Conferencia: Estructuras } \\
\text { de las proteínas }\end{array}$ & $\begin{array}{l}\text { Explicación sobre las } \\
\text { estructuras de las proteínas. } \\
\text { Gráfica de Ramachandrán } \\
\text { (lectura de artículos) }\end{array}$ & \\
\hline $\begin{array}{l}\text { Uso de herramientas } \\
\text { bioinformáticas }\end{array}$ & $\begin{array}{l}\text { Elaborar estructuras de } \\
\text { proteínas mediante } \\
\text { herramientas } \\
\text { bioinformáticas. }\end{array}$ & $\begin{array}{l}\text { RCSB PDB. } \\
\text { Psipred } \\
\text { Uppsala server }\end{array}$ \\
\hline Evaluación final & $\begin{array}{l}\text { Elaboración de un artículo } \\
\text { (Trabajo de grupos). } \\
\text { Cuestionario final } \\
\text { (Individual). }\end{array}$ & \\
\hline
\end{tabular}

\section{Resultados y discusión}

Teniendo en cuenta que la bioquímica abarca temáticas complejas, entre las cuales se destacan los conceptos asociados a las proteínas, tales como: aminoácidos, enlace peptídico, péptidos, proteínas, estructura primaria, secundaria, terciaria y cuaternaria, así como las diferentes funciones de las proteínas, sin olvidar los procesos metabólicos, invita

Sars CoV2, una experiencia de la bioquímica en contexto para la enseñanza de conceptos asociados a las proteínas. Rodrigo Rodríguez Cepeda y María José Cortés Parra.

Página 6 de 20 
a que los profesores diseñen actividades didácticas que favorezcan el aprendizaje de dichos conceptos.

En este sentido, el presente trabajo aporta con una propuesta de la enseñanza virtual de la bioquímica en contexto, y se limitó a un grupo de treinta estudiantes registrados en el tercer año del programa de Licenciatura en química y no se utilizó un grupo control, por lo que el estudio es exploratorio, pero permitió evidenciar algunas bondades del uso de herramientas bioinformáticas y de la enseñanza en contexto.

De esta manera, como actividad inicial, el grupo de estudiantes observo un video introductorio sobre el coronavirus Sars Cov2, elaborado por los autores de este artículo, el cual fue transmitido de forma virtual, con el fin de dar a conocer la definición de virus, las diferentes clases de coronavirus y como están estructurados, con énfasis en el Sars Cov2. En este sentido, la proteína $S$ fue utilizada como base para iniciar la enseñanza de los conceptos asociados a las proteínas, teniendo en cuenta el papel protagónico que tiene en el mecanismo de infección, igualmente, se realizó mención a las proteínas $\mathrm{E}$ y $\mathrm{N}$, con el fin de contextualizar la importancia de las proteínas en la enfermedad de Covid 19.

Con el fin de identificar el los conceptos bioquímicos más relevantes que los estudiantes lograron identificar, gracias al video introductorio, se les pidió que elaboraran un mapa conceptual, un mapa mental o un pictograma, con el cual debían resumir el video. En la figura 1 se presenta un ejemplo de mapa mental elaborado por un estudiante, con el cual se evidencia que el concepto central es coronavirus, alrededor del cual trata de plasmar las características generales, su estructura y la virología, en este último aspecto y mediante un dibujo, represente el nuevo coronavirus de forma esférica, la membrana biblipídica y la proteína $\mathrm{S}$, igualmente, muestra el proceso de infección que sucede en la célula, mediante las etapas de unión, fusión e internalización.

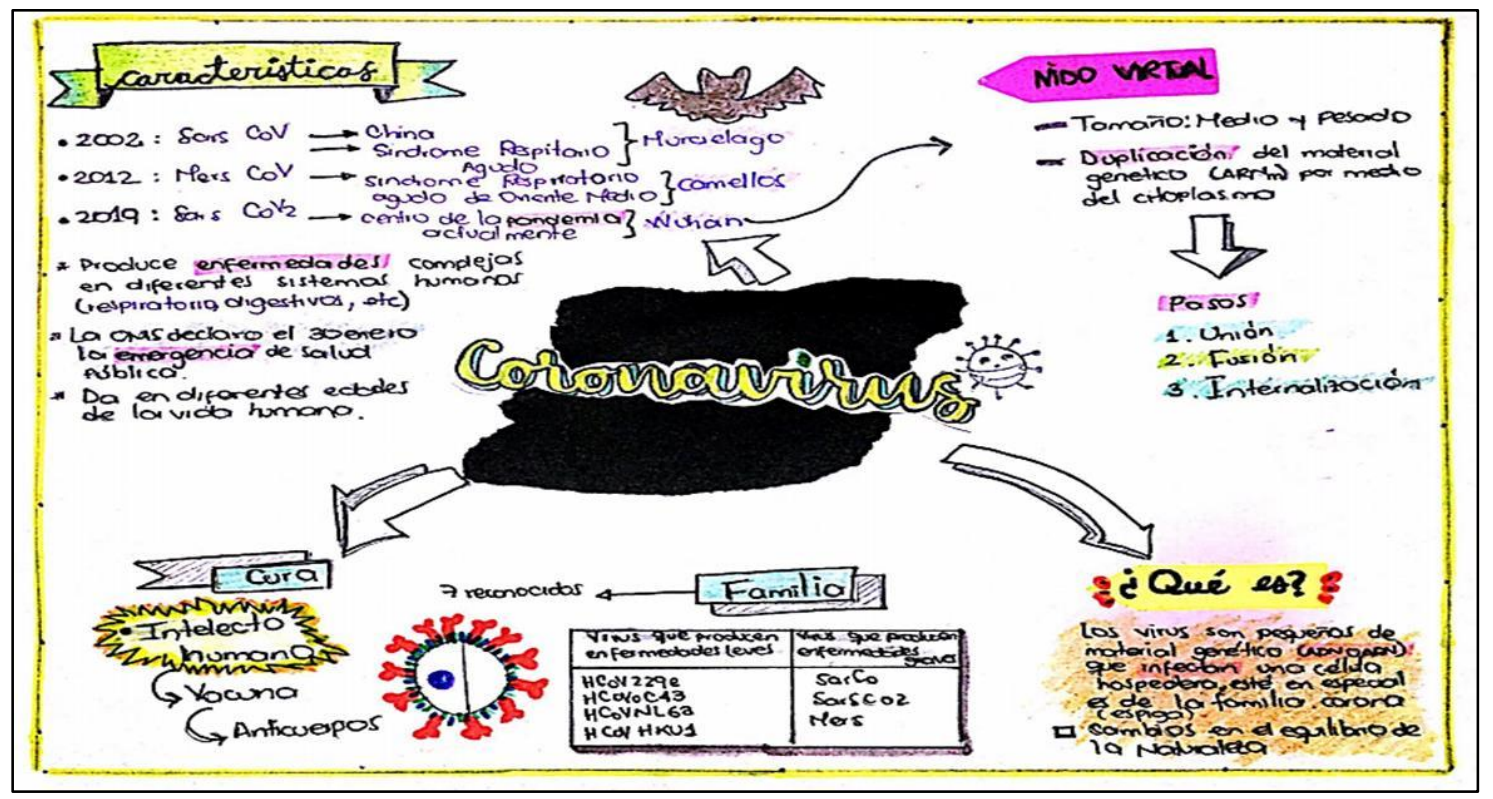

Figura 1: Mapa mental resumen del video, elaborado por Estudiante \# 1.

En este sentido, al analizar la totalidad de los mapas mentales presentados por los estudiantes, es posible suponer que la temática del coronavirus es un contexto ideal para introducir conceptos bioquímicos, debido a que despierta interés por la actualidad del

Sars CoV2, una experiencia de la bioquímica en contexto para la enseñanza de conceptos asociados a las proteínas. Rodrigo Rodríguez Cepeda y María José Cortés Parra. 
tema. Es claro que los estudiantes empiezan a apropiar algunos conceptos básicos de virología como por ejemplo: las familias, enfermedades que pueden causar, mecanismo de transmisión, la estructura del Sars Cov 2, además de lograr identificar los coronavirus que han causado pandemias durante el presente siglo.

En segunda instancia, se realizó una clase virtual, en la que los estudiantes plantearon algunos conceptos de interés y las razones por las que les interesaría profundizar en ellos (tabla 3), gracias a las inquietudes surgidas con el video.

Tabla 3: Conceptos de interés en los estudiantes, generados por el video y elaboración del mapa mental

\begin{tabular}{ll}
\hline Concepto de interés & Razones para profundizar \\
\hline Proteínas & $\begin{array}{l}\text { Porque hacen parte fundamental de la estructura del } \\
\text { Sars Cov2 }\end{array}$ \\
Síntesis de Proteínas & $\begin{array}{l}\text { Es importante por el papel que desempeña en la } \\
\text { traducción del material genético a partir del RNA }\end{array}$ \\
Enzima & $\begin{array}{l}\text { En el caso del virus, es importante para entender el } \\
\text { proceso de unión con la célula hospedera gracias a } \\
\text { la presencia de la Enzima Convertidora de } \\
\text { Angiotensina II (ECA II) }\end{array}$ \\
\hline Replicación del virus & $\begin{array}{l}\text { Entender este proceso permitiría entender el proceso } \\
\text { de réplica del virus y sus posible forma de detener } \\
\text { su expansión }\end{array}$ \\
\hline Membrana bilipídica & $\begin{array}{l}\text { Especialmente por la presencia de las proteínas S, E } \\
\text { y M, las cuales tienen diferentes funciones que } \\
\text { permiten la acción infecciosa del virus }\end{array}$ \\
\hline
\end{tabular}

Los resultados presentados en la tabla 3 muestran que los estudiantes tienen interés por conocer más a profundidad el papel que tienen algunas biomoléculas (proteínas y lípidos) en la estructura y en el proceso de infección del virus, además de considerar importante el código genético en la replicación de virus. Gracias a estos temas de interés, se desarrolló una serie de conferencias virtuales, en la que se abordaron conceptos básicos asociados a las proteínas, algunos de ellos fueron: aminoácidos, enlace peptídico, péptidos, proteínas, diagramas de distribución de cargas, punto isoeléctrico, estructura primaria, secundaria, terciaria y cuaternaria de las proteínas y gráfica de ramachanmdran, respaldadas con herramientas bioinformáticas (tabla 2), todas ellas alrededor de las proteínas presentes en el virus Sars Cov2.

Las actividades anteriores se complementaron con la lectura de artículos académicos, en los cuales se estudiaban las diferentes proteínas $(\mathrm{S}, \mathrm{E}, \mathrm{N})$ en relación con el papel infeccioso del Sars Cov2, el posible uso de la hidroxicloroquina como medicamento para el tratamiento de la enfermedad y sobre el mecanismo de infección del virus, además de la elaboración de ensayos individuales y grupales, basados en estas lecturas, además de ejercicios de lápiz y papel.

Los documentos entregados por los estudiantes se analizaron con el apoyo del software Atlas.ti, los cuales muestran que, en las etapas iniciales, después de observar el video introductorio y asistir a la conferencia inicial, los estudiantes plantean conceptos

Sars CoV2, una experiencia de la bioquímica en contexto para la enseñanza de conceptos asociados a las proteínas. Rodrigo Rodríguez Cepeda y María José Cortés Parra.

Página 8 de 20 
bioquímicos de forma aislada, con muy pocas relaciones entre ellos, por consiguiente, es posible suponer que existe una limitación en la estructura cognitiva de los estudiantes, quienes apelan únicamente a lo observado en el video, sin incluir otros conceptos básicos relacionados con las proteínas, como son los aminoácidos, enlace peptídico o estructuras de las proteínas. Por consiguiente, ante una pregunta que involucre estos conceptos, su respuesta sería muy limitada y con poco fundamento bioquímico, lo cual justifica la necesidad de profundizar en el aprendizaje de estos conceptos, con el fín de que sean integrados de mejor manera en la estructura cognitiva. En la figura 2 se presenta un ejemplo de una red conceptual del estudiante identificado con el número 2, y que evidencia lo analizado.

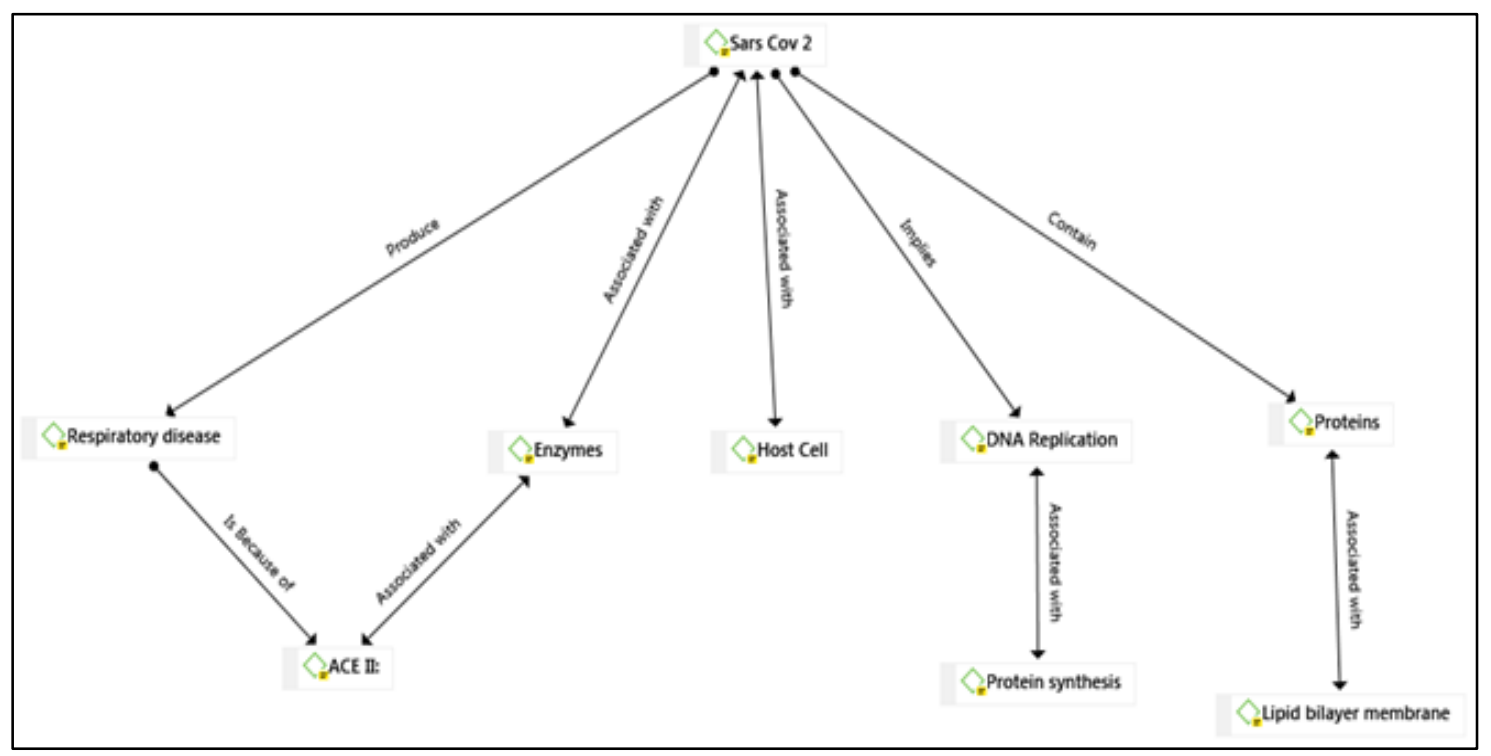

Figura 2: Red de conceptos estudiante 2, obtenido con el software Atlas.ti

Los documentos entregados por los estudiantes como producto de las actividades posteriores al video y a la conferencia inicial, evidencian que los conceptos principales sobre los cuales los estudiantes realizaron sus análisis están centrados en la replicación del virus, enzimas, Membrana bilipídica, Síntesis de proteínas y Proteínas. Además, se identificaron algunos conceptos secundarios como: ECA II , célula hospedera, enfermedad respiratoria, Sars $\mathrm{CoV} 2$, Fenómeno termodinámico, Apoptosis. En las figuras 3 y 4 se pueden observar las frecuencias de uso de los conceptos por parte de los estudiantes.

Sars CoV2, una experiencia de la bioquímica en contexto para la enseñanza de conceptos asociados a las proteínas. Rodrigo Rodríguez Cepeda y María José Cortés Parra. 


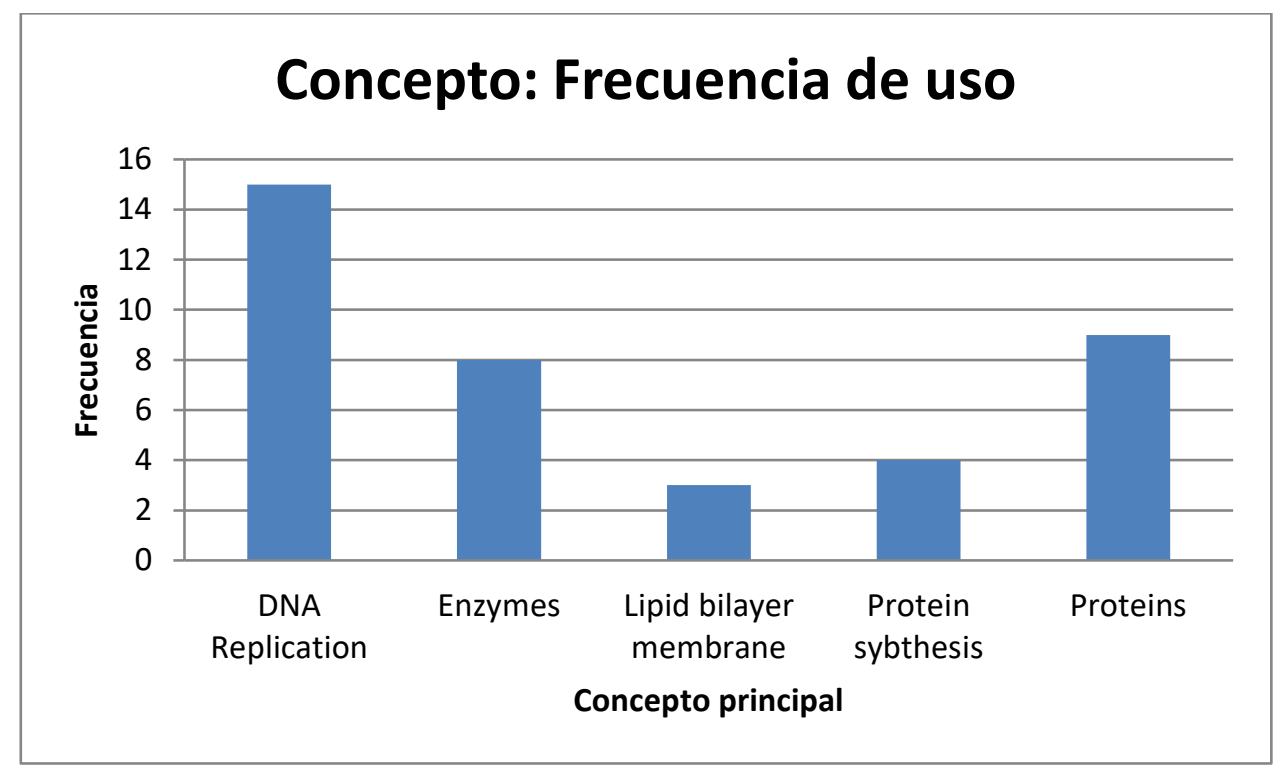

Figura 3: Frecuencia de uso de los conceptos principales por parte de los estudiantes

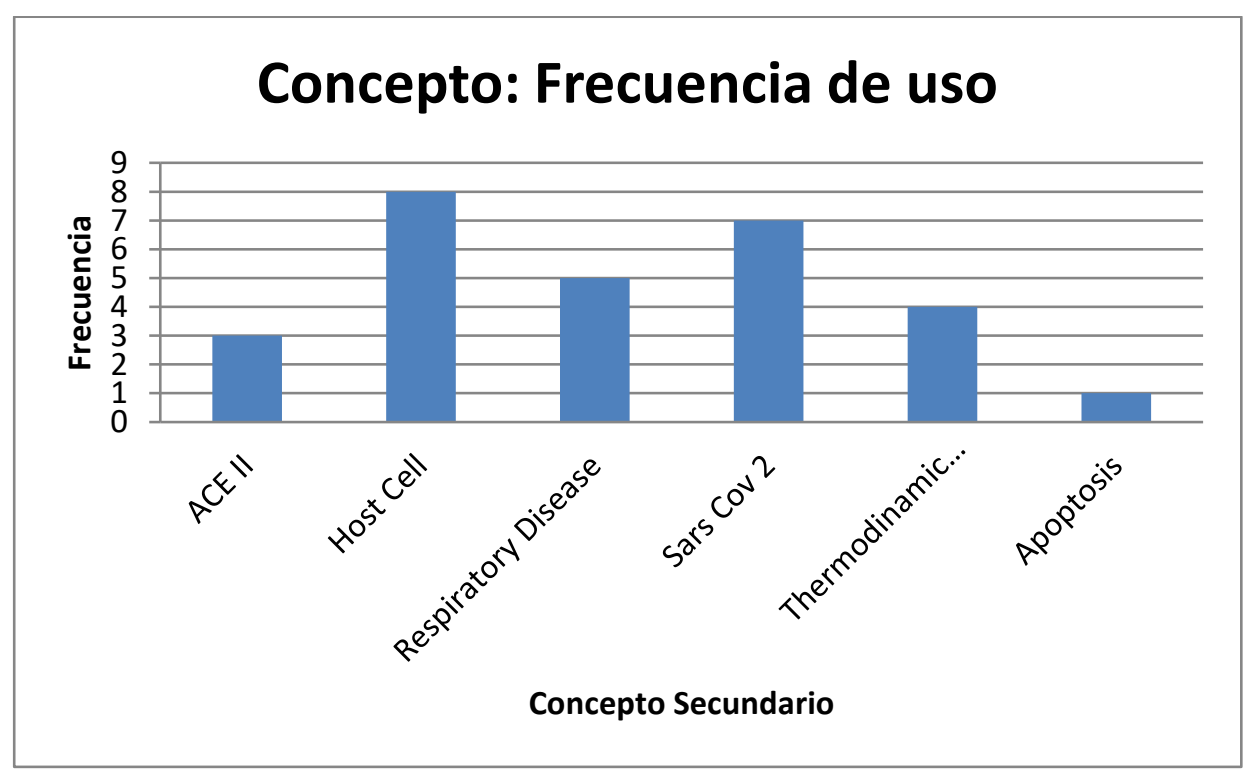

Figura 4: Frecuencia de uso de los conceptos secundarios por parte de los estudiantes

Los conceptos antes mencionados, permitieron enfocar las actividades de clase alrededor de los aminoácidos que conforman las proteínas $\mathrm{S}$ y $\mathrm{M}$ del coronavirus, especialmente en su estructura química, como actividad de lápiz y papel, los estudiantes propusieron agrupaciones de aminoácidos, teniendo en cuenta sus características químicas, físicas, estructurales o mixtas. En la tabla 4 se presenta un ejemplo de agrupación, elaborada por el estudiante 4.

Tabla 4: Clasificación de aminoácidos propuesta por el estudiante 4

\section{Clasificación propuesta}

\section{Aminoácidos}

Sars CoV2, una experiencia de la bioquímica en contexto para la enseñanza de conceptos asociados a las proteínas. Rodrigo Rodríguez Cepeda y María José Cortés Parra. 


\begin{tabular}{ll}
\hline & Triptófano \\
& Tirosina \\
& Histidina \\
\hline Alifáticos & Alanina \\
& Valina \\
& Leucina \\
& Isoleucina \\
& Glicina \\
\hline Azufrados & Metionina \\
& Cisteina \\
\hline Alifáticos con grupo hidroxilo & Serina \\
& Treonina \\
\hline Ácidos & Ácido aspártico \\
& Ácido Glutámico \\
\hline Amidas & Asparagina \\
& Glutamina \\
\hline Aminas & Lisina \\
\hline \multirow{2}{*}{ Alifático Cíclico } & Arginina \\
\hline
\end{tabular}

Si bien no es explícito, es posible concluir que la clasificación propuesta por el estudiante, la realiza sobre las características del sustituyente $\mathrm{R}$, especialmente por los grupos funcionales presentes. Es de resaltar la categoría nombrada como "alifáticos con grupo hidroxilo", ya que probablemente se refería al grupo funcional alcohol, este hecho podría evidenciar que el estudiante tiene algunas dificultades con el concepto grupo funcional. No obstante, se resalta que en general, los estudiantes hicieron usos de sus conocimientos químicos previos para proponer una alternativa de clasificación un poco diferente a las propuestas establecidas en los libros de texto.

Posteriormente, en una nueva actividad virtual, en la que se abordaron los conceptos de enlace peptídico, y las estructuras primaria, secundaria de las proteínas, además del uso de la gráfica de Ramachandran, apoyadas en el uso de las herramientas bioinformáticas reportadas en la tabla 2, para predecir la estructura secundaria de una de las proteínas del coronavirus. El manejo de las herramientas bioinformáticas les permitió a los estudiantes observar la estructura tridimensional de la proteína de una forma menos abstracta que mediante dibujos hechos en dos dimensiones, como tradicionalmente se ha realizado. En la figura 5 se presenta un ejemplo del trabajo realizado por el estudiante 5 , en la que se muestra la predicción de la proteína obtenida en la post-fusión de 6HB en Sars-Cov-2, reportada por Xi, S. et al. (2020).

Sars CoV2, una experiencia de la bioquímica en contexto para la enseñanza de conceptos asociados a las proteínas. Rodrigo Rodríguez Cepeda y María José Cortés Parra. 


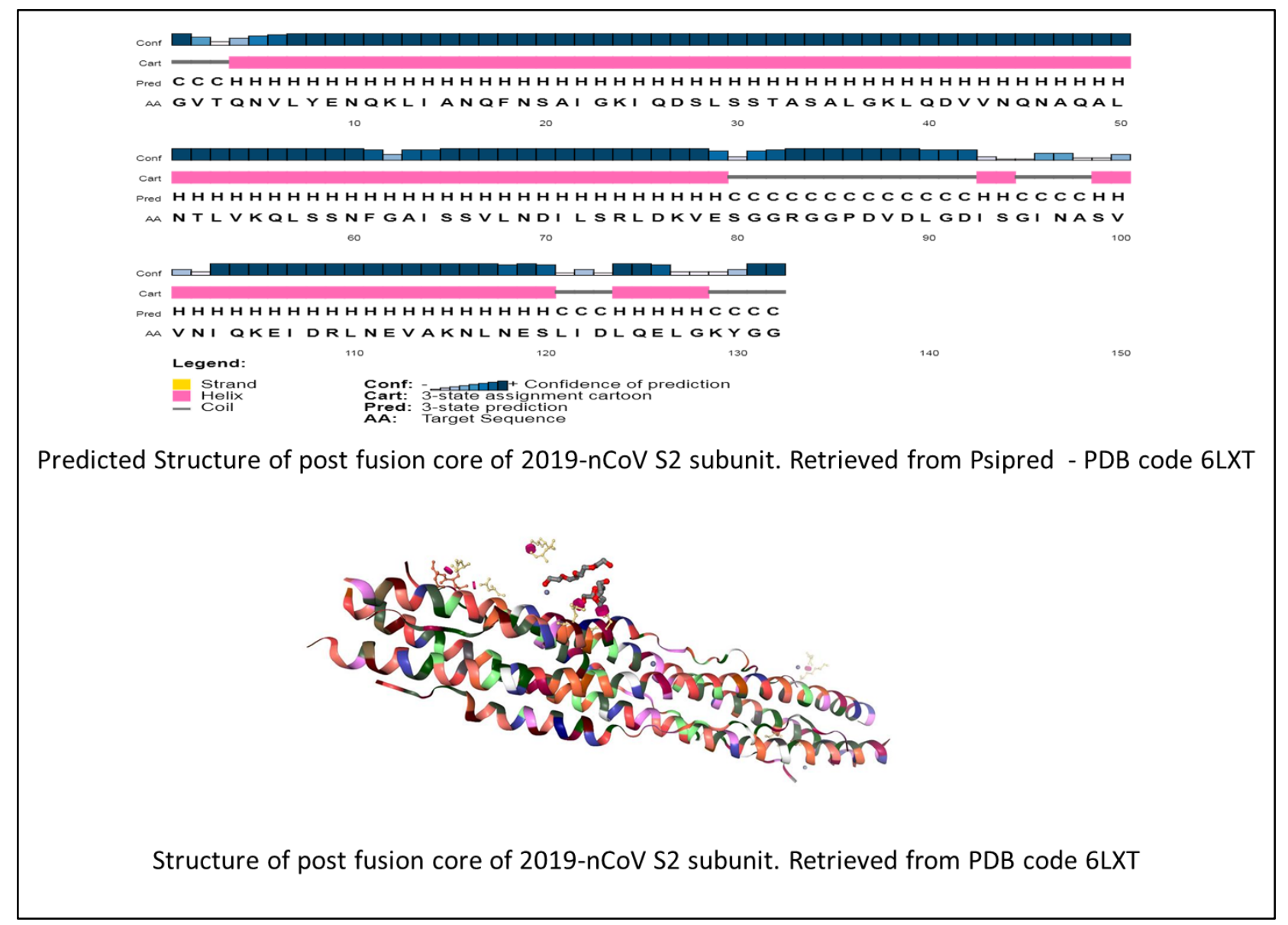

Figura 5: Predicción de la estructura secundaria realizada por el estudiante 5

Otro aspecto a resaltar es que, algunos estudiantes utilizaron la proteína $\mathrm{N}$ del Sars CoV, reportada en el artículo de Chen, C. et al., (2007), y registrada en el PDB como 2CJR, para obtener el gráfico de Ramachandrán, de la herramienta bioinformática Uppsala server, predecir la estructura secundaria y posteriormente corroborar su pronóstico con el software Psipred. A continuación, se presenta el ejemplo del estudiante 5, quien hace una reflexión general del tipo de estructura secundaria, apoyándose en la distribución por cuadrantes de la gráfica de Ramachandrán obtenida según lo presentado en la figura 6.

Estudiante 5: la gráfica nos muestra que la proteína tiene una alta densidad de puntos en el cuadrante superior e inferior izquierdo $\left(1^{\text {er }}\right.$ y $3^{\text {er }}$ Cuadrante), lo cual implica que la proteína tiene regiones con hoja $\beta$ y hélice $\alpha$ con giro a la derecha, estructura secundaria más estable energéticamente, pero me queda la duda frente a los puntos aislados en los otros cuadrantes.

Sars CoV2, una experiencia de la bioquímica en contexto para la enseñanza de conceptos asociados a las proteínas. Rodrigo Rodríguez Cepeda y María José Cortés Parra. 


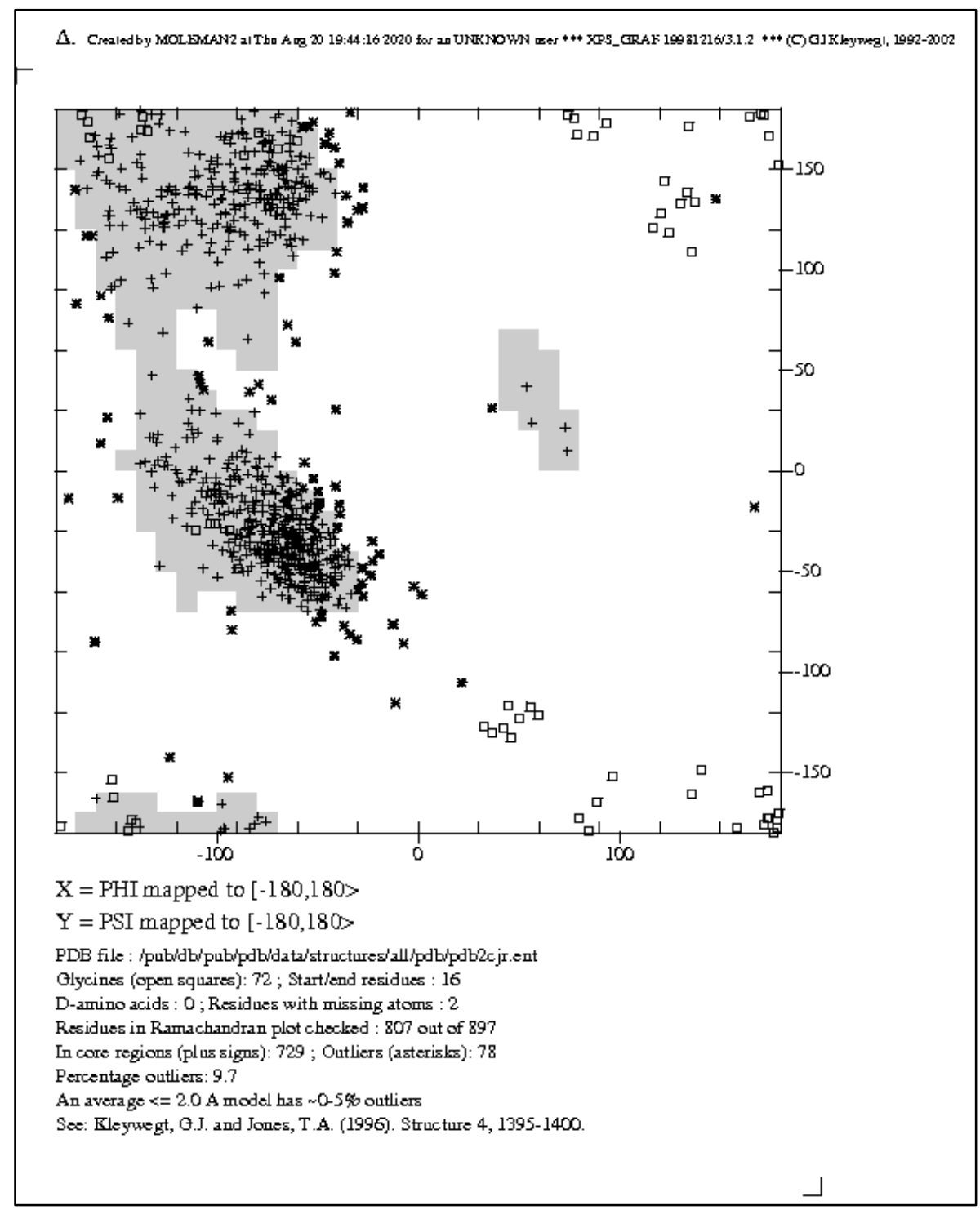

Figura 6: Gráfica de Ramachandran obtenida y analizada por el estudiante 5

De acuerdo con el análisis realizado por el estudiante 5, es posible suponer que el uso de la gráfica de Ramachandran, le ha dado herramientas para proponer una estructura secundaria energéticamente estable, este mismo resultado se observa claramente en las opiniones de los otros estudiantes que participaron en el ensayo.

Después de los ejercicios con herramientas bioinformáticas, los estudiantes se organizaron por grupos de trabajo y elaboraron un resumen general de los temas trabajados alrededor de las proteínas. Las condiciones para elaborar el resumen fueron: A) tener la estructura de un artículo reflexivo, en el cual, los estudiantes podían consultar fuentes bibliográficas, pero se debía consolidar un análisis crítico personal de cada concepto abordado; B) La discusión central debería estar en el contexto de la pandemia por Covid 19; C) Incluir algunos conceptos nuevos que ayudarán a complementar las temáticas abordadas, siempre que estuvieran perfectamente documentados. Este trabajo en grupos permite el trabajo colaborativo entre los participantes, con lo cual se pretendió que el aprendizaje individual se reforzara con las fortalezas de cada individuo que participa en el grupo. Los documentos en forma de artículos fueron analizados por medio

Sars CoV2, una experiencia de la bioquímica en contexto para la enseñanza de conceptos asociados a las proteínas. Rodrigo Rodríguez Cepeda y María José Cortés Parra. 
del software Atlas.ti, para lo cual se emplearon como criterios de análisis, los mismos conceptos principales definidos en el análisis del ejercicio inicial (tabla 3).

En la figura 7 se observa un ejemplo de red de conceptos obtenida del análisis realizado al artículo, en la cual se puede observar una mayor complejidad que el obtenido en el instrumento inicial, el cual analizaba el video introductorio y la primera conferencia virtual del profesor, por consiguiente, es posible presumir que la intervención didáctica le permitió a los estudiantes asimilar conceptos nuevos en su estructura cognitiva y crear relaciones con los conceptos iniciales que se identificaron en el primer ejercicio (Tabla 3, figura 2).

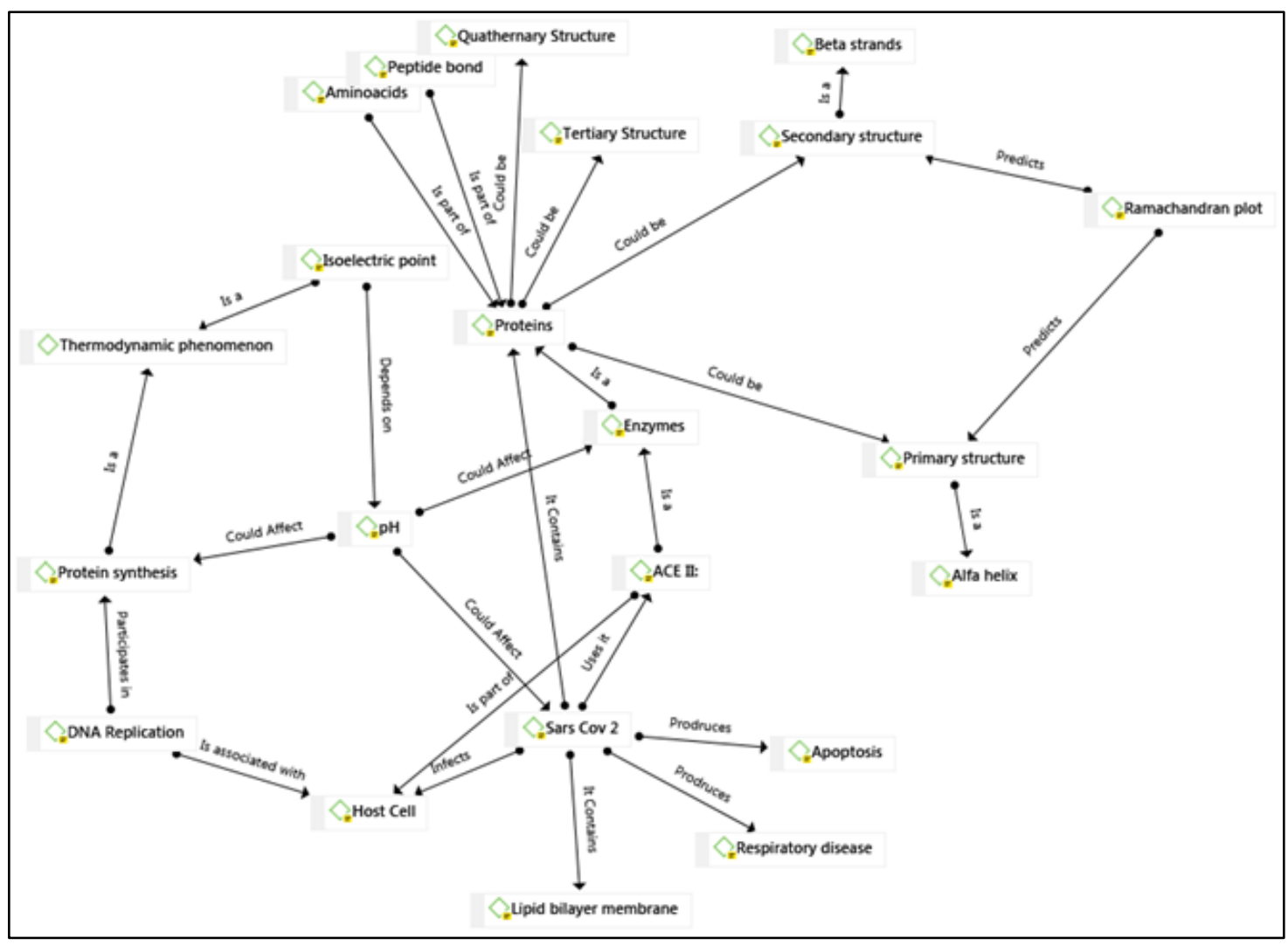

Figura 7: Red de conceptos obtenida del resumen final, obtenido en el software Atlas.ti

De hecho, la red de conceptos presentada en la figura 7, muestra tres conceptos centrales sobre los cuales los estudiantes desarrollaron su análisis, estos son: Sars Cov 2, Proteínas y $\mathrm{pH}$. Con respecto al Sars Cov2 se resalta que los estudiantes no solamente relacionan las proteínas sino que incluyen conceptos nuevos, no abordados hasta el momento, como son: Enzimas, Replicación del DNA, síntesis de proteínas, fenómenos termodinámicos y punto isoeléctrico, lo cual parece demostrar que los nuevos conocimientos no se construyen aisladamente, por el contrario, los estudiantes elaboran relaciones con otros conceptos asociados a las proteínas.

Por otra parte, el $\mathrm{pH}$ emerge como un concepto central sobre el cual se relacionan conceptos y fenómenos bioquímicos importantes como el punto isoeléctrico o el posible efecto sobre la síntesis de proteínas o en los procesos de infección por parte del virus. Por

Sars CoV2, una experiencia de la bioquímica en contexto para la enseñanza de conceptos asociados a las proteínas. Rodrigo Rodríguez Cepeda y María José Cortés Parra. 
otra parte, con el concepto de proteínas se relacionan los aminoácidos, enlace peptídico, las estructuras primaria, secundaria y el gráfico de Ramachandran, abordados como ejes centrales en las actividades didácticas realizadas en la intervención, además de los anteriores conceptos, los estudiantes incluyen nuevos conceptos como las estructuras terciaria y cuaternaria, entre otros, lo cual permite suponer que las actividades y temáticas abordadas, despertaron el interés de los estudiantes, por lo que la indagación de conceptos asociados a los trabajados en clase, fueron considerados importantes para explicar los fenómenos bioquímicos alrededor del Sars Cov2. En la figura 8 se puede observar las frecuencias de uso de los conceptos por parte de los estudiantes.

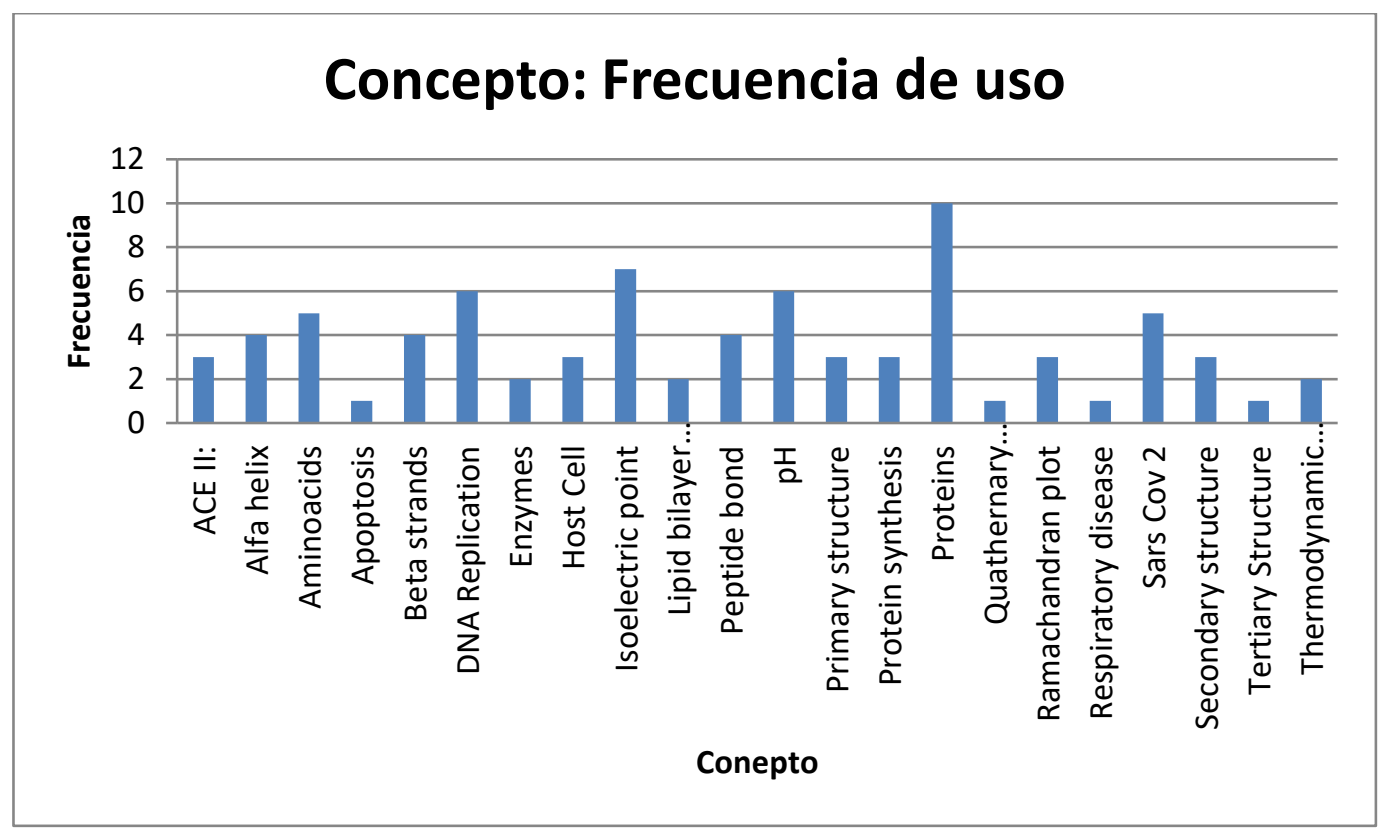

Figura 8: Frecuencia de uso de los conceptos por parte de los estudiantes

De acuerdo con los resultados observados en la figura anterior, se puede mencionar que los conceptos más utilizados por los estudiantes son: proteínas, Replicación de DNA, pH, Sars Cov 2 y Amino ácidos, con lo que se puede suponer que la intensión de enseñar los conceptos asociados a las proteínas en el contexto del Sars Cov 2 y el uso de herramientas bioinformáticas se cumplió, además de generar en los estudiantes el interés por estudiar nuevos conceptos relacionados con este contexto, este resultado es consistente con estudios previos reportados en la literatura (Badotti, Barbosa, Martins, Do Valle, \& Mainá, 2014; Koch \& Fuellen, 2008).

Finalmente, se aplicó un cuestionario final, en el cual se les pidió a los estudiantes dibujar una posible estructura secundaria de la fracción de proteína 6LXT del PDB (figura 5), comprendida entre los amino ácidos 1 y 19, teniendo en cuenta el modelo obtenido mediante la herramienta Psipred. Igualmente, debían determinar la distribución de cargas en función del $\mathrm{pH}$, representada mediante una gráfica de distribución de cargas. En la figura 9 se muestra un ejemplo de la estructura secundaria y la gráfica de distribución de cargas elaboradas por el estudiante 10.

Sars CoV2, una experiencia de la bioquímica en contexto para la enseñanza de conceptos asociados a las proteínas. Rodrigo Rodríguez Cepeda y María José Cortés Parra. 


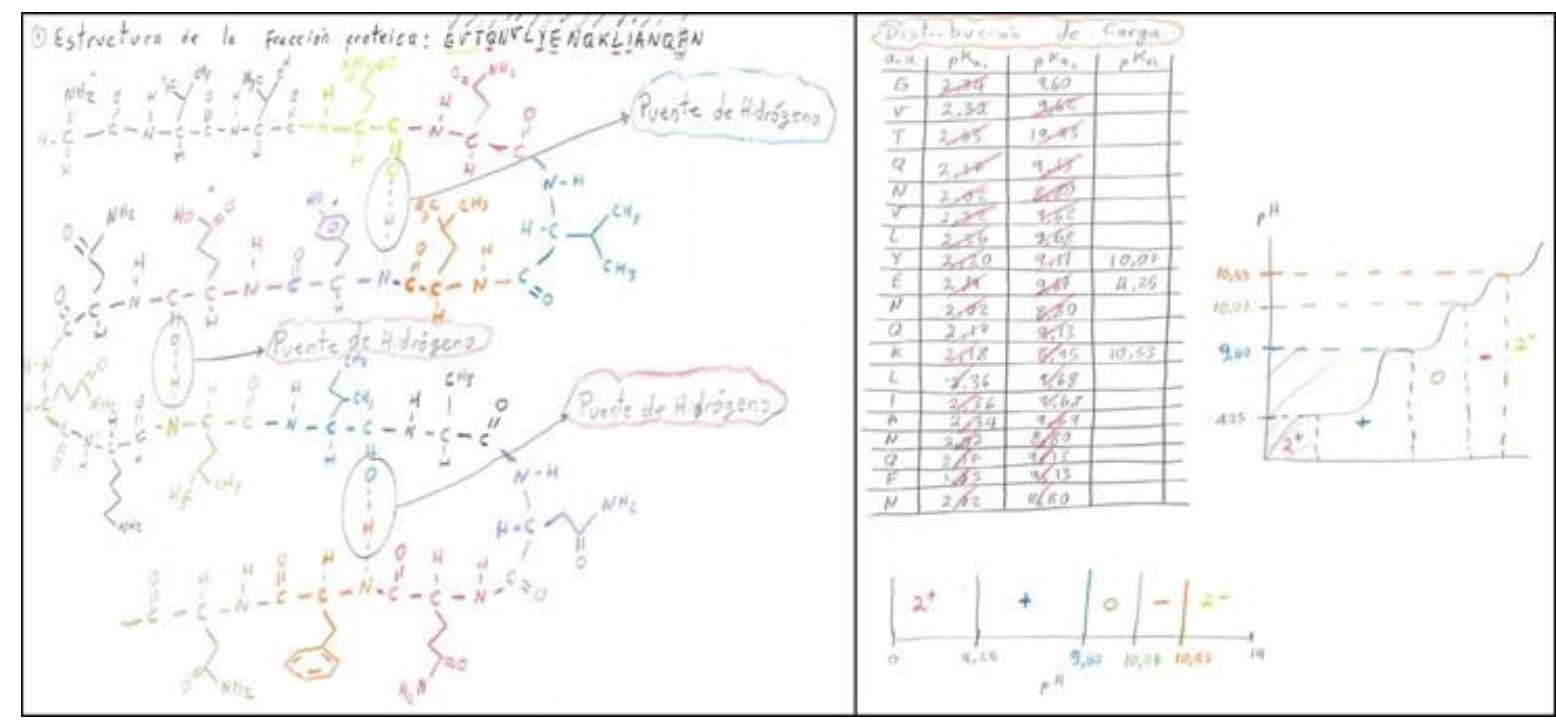

Figura 9: Estructura secundaria y distribución de cargas de la proteína 6LXT recuperada del PDB. Estudiante 10

Frente a la estructura propuesta, el estudiante 10 analiza:

Estudiante 10: De acuerdo con el programa Psipred, los tres primeros aminoácidos no forman una estructura secundaria definida y en adelante, la proteína tiene una estructura secundaria alfa hélice, por lo que elaboré el puente de hidrógeno entre el carbonilo del aminoácido cuatro (glutamina) y el a.a. $n+4$ (tirosina) y así sucesivamente.

El dibujo y la distribución de carga en la fracción de proteína propuesta por el estudiante 10 son similares a las propuestas por otros estudiantes, por lo que se evidencia el progreso en la comprensión de los conceptos aminoácidos, enlace peptídico, proteínas, estructura primaria, estructura secundaria, distribución de cargas y punto isoeléctrico, gracias a las actividades virtuales en contexto y al uso de herramientas bioinformáticas, resultado que complementa los reportados por otros investigadores (Lohning, Hall, \& Dukie, 2019; Macaulay, Van Damme, \& Walker, 2009).

\section{Conclusiones}

Teniendo en cuenta que la comunidad científica reconoce que la bioquímica abarca temas complejos, los cuales, tradicionalmente han sido enseñados mediante una metodología memorística, cuyo resultado es el bajo rendimiento académico o la desmotivación por el aprendizaje, es de gran importancia que los profesores diseñen y apliquen nuevas metodologías de enseñanza, para mejorar la experiencia en el aula y facilitar el proceso de aprendizaje de los estudiantes. Una propuesta que pretende aportar en esta vía, es la enseñanza de la bioquímica en contexto, sobre la cual el presente trabajo se desarrolló, con el fin de proponer actividades virtuales enfocadas al aprendizaje de algunos conceptos asociados a las proteínas, en el contexto del Sars Cov2.

Sars CoV2, una experiencia de la bioquímica en contexto para la enseñanza de conceptos asociados a las proteínas. Rodrigo Rodríguez Cepeda y María José Cortés Parra. 
Como resultado de esta intervención didáctica, se puede observar que los estudiantes participantes, contaban con unos conceptos iniciales sobre proteínas un poco limitados y desarticulados, aprendidos probablemente por un ejercicio memorístico preliminar. Este hecho se evidencia en el mapa mental inicial, en el cual no observan relaciones cruzadas entre conceptos, ni con otros aspectos propios de la bioquímica, es claro que, los conceptos utilizados para elaborar el mapa solamente hacen referencia a los mencionados en el video introductorio sobre el coronavirus Sars Cov2 y que los estudiantes no realizaron una indagación en fuentes bibliográficas, para complementar el mapa mental.

No obstante, las actividades iniciales (video introductorio y conferencia inicial) evidencian que los estudiantes desarrollaron interés en profundizar sobre temas como proteínas, síntesis de proteínas y enzimas, entre otras temáticas, todas ellas alrededor del Sars Cov2, ya que empiezan a apropiar conceptos relacionados con la virología. Este aspecto refuerza la importancia de la enseñanza de la bioquímica en contextos diversos, especialmente en aquellos que resultan de interés para los estudiantes.

El uso de herramientas bioinformáticas como apoyo para la enseñanza de conceptos asociados a las proteínas, permiten mejorar la asimilación de estos conceptos, a los cuales se les reconoce su alto nivel de complejidad y de abstracción, y que resultan de gran dificultad para ser entendidos por parte de los estudiantes. Adicionalmente, el uso de estas herramientas permite fortalecer las habilidades de consulta, manejo de bases de datos y análisis de información bioquímica actualizada, además de propiciar un ambiente de aprendizaje interesante para los estudiantes.

Es razonable pensar que las actividades realizadas en el contexto del Sars Cov2 permitieron la comprensión, asimilación y construcción de conceptos asociados a las proteínas, tales como: aminoácidos, enlace peptídico, proteínas, estructura primaria y estructura secundaria, además de servir como tema de introducción para temas como: estructuras terciaria y cuaternaria, enzimas, síntesis de proteínas, procesos relacionados con el código genético y fenómenos termodinámicos asociados a la bioquímica, lo cual se evidencia con el artículo y el cuestionario resuelto por los estudiantes como actividad final.

\section{Agradecimientos}

El autor desea agradecer a la Universidad Pedagógica Nacional y al grupo de investigación de Didáctica y sus Ciencias por su apoyo, pero especialmente a los estudiantes registrados en el curso de Sistemas Bioquímicos 2020-I, quienes participaron en el presente ejercicio didáctico.

Presentación del artículo: 25 de enero de 2021

Fecha de aprobación: 28 de julio de 2021

Fecha de publicación: 30 de septiembre de 2021

Sars CoV2, una experiencia de la bioquímica en contexto para la enseñanza de conceptos asociados a las proteínas. Rodrigo Rodríguez Cepeda y María José Cortés Parra. 
Rodríguez Cepeda, R. \& Cortés Parra, M.J. (2021). Sars CoV2, una experiencia de la bioquímica en contexto para la enseñanza de conceptos asociados a las proteínas. RED. Revista de educación a distancia, 21(67). http://dx.doi.org/10.6018/red.465221

\section{Financiación:}

El presente artículo hace parte del proyecto de investigación: "Enseñanza-aprendizaje de conceptos químicos en el contexto de la química de alimentos, un espacio para la formación de investigadores" DQU-027-S-020, financiado por el Centro de Investigaciones - Subdirección de gestión de proyectos de la Universidad Pedagógica Nacional (CIUP).

\section{Referencias Bibliográficas}

Badotti, F., Barbosa, A., Martins, A., Do Valle, Í., \& Mainá, L. (2014). Comparative Modeling of Proteins: A Method for Engaging Students Interest in Bioinformatics Tools. Biochemistry and Molecular Biology Education, 42(1), 68-78.

Berman, H., Westbrook, J., Feng, Z., Gilliland, G., Bhat, T., Weissig, H., y otros. (2000). The Protein Data Bank. Nucleic Acids Research, 28(1), 235-242.

Berry, C., \& Baker, M. (2010). Multimedia in Biochemistry and Molecular Biology Education. Biochemistry and Molecular Biology Education, 38(6), 425-429.

Boyd-Kimball, D., \& Miller, K. (2018). From CookbooK to Research: Redesigning and Advanced Biochemistry. Journal of Chemical Education, 95(1), 62-67.

Buchan, D., \& Jones, D. (2019). The PSIPRED Protein Analysis Workbrench: 20 Years on. Nucleic Acids Research, 47(W1), 402-407.

Chemaxon. (1998). Chemaxon. Recuperado el 30 de January de 2020, de https://chemaxon.com/

Chen, C., Chang, C. K., Chang, Y. W., Sue, S. C., Bai, H. I., Riang, L., y otros. (2007). Structure of the Sars Coronavirus Nucleocapsid Protein RNA-Binding Dimerization Domain Suggests a Mechanism for Helical Packaging of Viral RNA. Journal of Molecular Biology, 368(4), 1075-1086.

Cookmeyer, D., Winesset, E., Kokona, B., Huff, A., Aliev, S., Bloch, N., y otros. (2017). Uncovering Protein-Protein Interactions Througha Team-Based Undergraduate Biochemistry Course. Plos Biology, 15(11), 1-13.

Dallakyan, S., \& Olson, A. (2015). Small-molecule Library Screening by Docking with PyRx. Methods in Molecular Biology, 1263, 243-50.

Sars CoV2, una experiencia de la bioquímica en contexto para la enseñanza de conceptos asociados a las proteínas. Rodrigo Rodríguez Cepeda y María José Cortés Parra. 
Dorfman, B., Terrill, B., Patterson, K., Yarden, A., \& Blonder, R. (2019). Teachers Personalize Videos and Animations of Biochemical Processes: Results from a Professional Development Workshop. Chemistry Education Research and Practice(4), 772-786.

Fardilha, M., Schrader, M., da Cruz e Silva, O., \& da Cruz e Silva, E. (2010). Understanding Fatty Acid Metabolism Trought an Active Learning Approach . Biochemistry and Molecular Biology Education, 38(2), 65-69.

Kim, S., Chen, J., Cheng, T., Gindulyte, A., He, J., He, S., y otros. (2019). PubChem 2019 Update: Improved Access to Chemical Data. Nucleic Acids Research, 47(D1), D1102-D1109.

Kleywget, G., \& Jones, A. (1996). Phi/Psi-chology: Ramachandran revisited. Ways \& Means, 4(12), 1395-1400.

Koch, I., \& Fuellen, G. (2008). A Review of Bioinformatics Education in Germany. Briefings in Informatics, 9(3), 232-242.

Lang, F., \& Bodner, G. (2020). A Review of Biochemistry Education Research. Journal of Chemical Education, 97(8), 2091-2103.

Linenberger, K., \& Bretz, S. (2014). Biochemistry Students'Ideas About Shape and Charge in Enzyme-Substrate Interactions. Biochemistry and Molecular Biology Education, 42(3), $203-$ 212.

Lohning, A., Hall, S., \& Dukie, S. (2019). Enhancing Understanding in Biochemistry Using 3D Printing and Cheminformatics Technologies: A Student Perspective. Journal of Chemical Education, 96(11), 2497-2502.

Macaulay, J., Van Damme, M., \& Walker, K. (2009). The Use of Contextual Learning to Teach Biochemistry to Dietetic Students. Biochemistry and Molecular Biology Education, 37(3), 137-143.

Michael, J. (2006). Where's the Evidence that Active Learning Works? Advances in Physiology Education, 30(4), 159-167.

Mutlu, A. (2018). Comparison of Two Different Techniques of Cooperative Learning Approach: Undergraduates'Conceptual Understanding in the Context of Hormone Biochemistry. Biochemmistry and Molecular Biology Education, 46(2), 114-120.

Nagaiah, B., Gowda, V., \& Jeyachristy, S. (2014). Motivating First Year Medical Students to Learn Biochemistry by Case Based Learning. International Journal of Biomedical Research, 5(7), 461-464.

Rodríguez , J., Hux, N., Philips, S., \& Towns, M. (2019). Michaelis - Menten Graphs, Lineweaver-Burk Plots, and Reactions Schemes: Investigating Introductory Biochemistry Students'Conceptions of Representations in Enizyme Kinetics. Journal of Chemical Education, 96(9), 1833-1845.

Rodríguez, R. (2018). Los modelos de aprendizaje de Kolb, Honey y Mumford: Implicaciones para la educación en ciencias. Sophia, 14(1), 51-64.

Sars CoV2, una experiencia de la bioquímica en contexto para la enseñanza de conceptos asociados a las proteínas. Rodrigo Rodríguez Cepeda y María José Cortés Parra. 
Rodriguez, R., Casas, J., \& Martínez, D. (2020). Laboratorio de Química Bajo Contexto: Insumo para el Desarrollo de Habilidades de Pensamiento Crítico. Tecné, Episteme, Didaxis(47), 3352.

Romero, R., Espinosa, L., \& Ramírez, D. (2019). Organic Chemistry Basid Concepts Teaching in Students of Large Groups at Higer Education and Web 2.0 Tools. Actualidades Investigativas en Educación, 19(1), 1-31.

Rowe, L. (2017). Green Fluorescent Protein-Focused Bioinformatics Laboratory Experiment Suitable for Undergraduates in Biochemistry Courses. Journal of Chemical Education, 94(5), 650-655.

Schönborn, K., \& Anderson, T. (2006). The Importance of Visual Literacy in the education of Biochemists. Biochemistry and Molecular Biology Education, 34(2), 94-102.

Smith, J., Harris, J., López, O., Valverde , L., \& Borchert, G. (2015). "On the job" Learning: A Bioinformatics Course Incorporating Undergraduates in Actual Research Projects and Manuscripts Submissions. Biochemistry and Molecular Biology Education, 43(3), 154-161.

Stasinakis, K., \& Despoina, N. (2017). Modeling of DNA and Protein Organization Levels with Cn3D Software. Biochemistry \& Molecular Biology Education, 45(2), 126-129.

Sun, J., Tang, Y., Sa, R., \& Gao, Y. (2019). Predicting and Visualizing 5S rRNA Structures Using Bioinformatics Tools to Help Students Learn RNA Structure and Function while Gaining Computer Research Skills. Journal of Chemical Education, 96(11), 2611-2616.

Vaughan, N. (2007). Perspectives on Blended Learning in Higher Education. International Journal on E-Learning, 6(1), 81-94.

Wheeler, L., Maeng, J., \& Whitworth, B. (2015). Teaching Assintants'Perceptions of a Training to Support an Inquiry-Based General Chemistry Laboratory Course. Chemistry Education Research and Practice(16), 824-842.

Xia, S., Liu, M., Wang, C., Xu, W., Lan, Q., Feng, S., y otros. (2020). Inhibition of SARS-CoV2 (Previously 2019-n Cov) Infection by a Highly Potent Pan-coronavirus Fusion Inhibitor Targeting its Spike Protein that Harbors a High Capacity to Mediate Membrene Fusion . Cell research(30), 343-355.

Zardecki, C., Dutta, S., Goodsell, D., Voigt, M., \& Burley, S. (2016). RCSB Protein Data Bank: A Resource for Chemical, Biochemical, and Structural Explorations of Large and Small Biomolecules. Journal of Chemical Education, 93(3), 569-575.

Sars CoV2, una experiencia de la bioquímica en contexto para la enseñanza de conceptos asociados a las proteínas. Rodrigo Rodríguez Cepeda y María José Cortés Parra. 